\title{
Application of Infrared Spectroscopy in the Detection of Coal Quality of Power Plant
}

\author{
J.J. Liu, X. Zhao, J.B. Zhang, Q.B. An, D.F. Luan, H. Men \\ College of automation engineering, Northeast Dianli University \\ Jilin Jilin, China
}

\begin{abstract}
Spectrum technology in coal quality detection has become a research hotspot with the maturing of spectral technology and the continuous development of spectral imager. This article mainly analyzed and summarized the progress and research status of scholars at home and abroad based on the coal quality index (moisture, ash content, volatile matter, fixed carbon and sulfur content).According to the coal quality index, we demonstrated spectrum technology has considerable prospects in coal quality testing by analysis the application of spectrum technology in detection of other material's corresponding index.
\end{abstract}

Keywords-infrared spectroscopy; wave length; coal quality; moisture; power plant

\section{INTRODUCTION}

Coal was the food of coal-fired power plants and take up about 70 percent of the total electricity cost in power plant. To determine the coal quality in the construction of power plants was an important basic work, which was related to the stability and reliability of the boiler operation [1]. There had not yet set a unified technical standard for the determination of coal in our country.

Many scholars detected coal quality indicators (moisture, ash content, volatile matter, fixed carbon and sulfur content) through the traditional physical and chemical methods. The determination of moisture in coal mainly through nitrogen drying, air drying, microwave drying method. The method of determination of ash content in coal was slow ashing method and rapid ashing method. There were many methods of determination of total sulfur, airy method was a general standard method for determination of total sulfur in coal in many countries [2]. The determination of volatile matter in coal indexes usually adopted the method of measuring burning heavy and calculating the loss of coal sample, the calculated results minus the water content of coal sample could obtained the volatile matter of coal samples. By understanding the traditional method on the analysis of coal quality indicators, a lot of disadvangtages were found in traditional methods, such as low accuracy, interference factors, easily affected by environment and personnel and easy to produce harmful gas. So other secure and high accurate methods should be tried.

As was known to all that spectral analysis was an important means of study natural science. The physical structure and chemical composition of the object could be detected by spectroscopy. Spectral imaging technology was the inevitable result of the development of spectral analysis technique and image analysis technology. Spectral imaging technology not only has a higher spectral resolution but also has the image resolution. therefore, by using spectral imaging technique could detect objects with qualitative analysis, quantitative analysis and the positioning analysis[3].

\section{THE RESEARCH PROGRESS OF SPECTRAL IMAGING IN THE DETECTION OF COAL}

The industry analysis of the coal was the main content of coal quality analysis in the laboratory; coal industry analysis was called the technical analysis of coal or practical analysis, including moisture, ash, volatile, sulfur, and fixed carbon, etc, used as the fundamental basis for evaluation of coal quality. Many scholars at home and abroad using spectrum technology have obtained certain achievements in coal quality analysis. For coal quality indicators, a lot of literatures choose reasonable band to build the model based on their spectral characteristics, or according to the relationship between these indicators, such as ultivariate linear relationship, to optimize model and obtain higher accuracy.

Mikio Kaihar[4] studied the relationship of some main performance indicators of the coal and near-infrared spectroscopy, they established a model to simulate the spectrum analysis by PLS and analyzed the correlation coefficient of multiple indicators, but the accuracy is not high.J.M. Andres and M.T.Bona[5-7] tested the relationship between multiple indicators(moisture, ash, volatile matter, fixed carbon, sulfur) that effected the qualtity of the coal by using Near Infrared Spectroscopy and Multivariate Analysis Technology. Also they improved the prediction ability of the variable through building the model of PLS and PCA. Dong Won Kim [8] used Near Infrared Spectroscopy to analysis the quality indicators of coal (moisture, ash, volatile matter and fixed carbon) and Internal element (carbon, hydrogen, nitrogen, oxygen and sulfur). According to the properties of coal, they chose the optimal wave band (1680, 1942, 2100, 2180, 2300nm) for modeling and the on-line detection of coal analysis was realized. Yasheng Wang [9] analyzed the quality of coal by NIRS and built Near-infrared spectroscopy regression model of PLS, The results showed that the accuracy of Fixed carbon and volatile was high, but the accuracy of Moisture, ash, sulfur was not high. Zhongsheng Li and Peter M. Fredericks [10] of Australia achieved a chemical efficacy testing of Low-sulfur coal by use of NIRS.

Fengrui Li [11] used multiple regression methods for data analysis and established the regression equation between the water value and absorbance, also they predicted the moisture 
value by absorbance. Hongwei Yan [12] researched fast nondestructive testing of coal ash and sulfur content with NIRS. They established quantitative detection of principal component regression model through studying the internal composition of the Pulverized coal sample. Yangyang Zhai[13] and others used the partial least-squares regression algorithm, and studied the coal ash rapid detection method based on the near-infrared diffuse reflection spectrum , they established the coal ash and mathematical regression model between the near-infrared diffuse reflection spectrum. They used the actual experimental researches on the ash ofcoal samples and achieved better analysis and more relatively stable model. Fengrui Li[14] established multiple linear regression equation between the volatile matter and absorbance, predicted the volatile through the absorbance, but the near infrared spectral absorption was influenced by the particle size, particle dense degree, and other factors, so the research of volatile still has a lot of work to do.

\section{SPECTROSCOPY APPLICATION IN OTHER RELATED FIELDS}

For coal quality index, there were the same ingredients like coal components (moisture, ash content, volatile matter, fixed carbon) in other material, such as straw, pine, fir, etc. In the agriculture and forestry biological detection, many scholars applied spectrum technology and made a lot of experiments and research, they have made some progress.

Sandeson[15] studied and tested the raw material chemical composition of some wood and herb used near infrared reflectance spectra. Labbe[16] determinated the ash content and carbon content of three kinds of wood (red oak, boxwood, walnut) and three kinds of herbs(switchgrass, maize straw and bagasse) rapidly and respectively used near infrared spectroscopy combined with nonlinear nuclear transformation method. Allison[17] used Fourier transform infrared spectrum method to analyz the main components (nitrogen content, index of alkali metal, carbon content and ash content) for two kinds of energy plant (switchgrass and reed). Fagan[18] used near infrared spectroscopy to determine the composition (moisture, ash content and carbon content) and calorific value of a miscanthus and two types of salix energy crop. Sivakumar[19] compose a application high imaging spectroscopy on the moisture content of the mango research, measure the spectral range $400-1000 \mathrm{~nm}$. The results showed that the moisture of mango correlation coefficient was 0.81 by use of artificial neural network. It suggested that the optimal wavelength selection of mango moisture content was 831,923,950.

Lujia Han[20] and others applied near infrared spectrometer in $1108 \sim 2492 \mathrm{~nm}$ spectral range to establish the predict model of direct cut short straw samples in the aspect of moisture, ash content, volatile ,fixed carbon and the drying crushing samples in the aspect of ash content, volatile, fixed carbon. The results showed that the rapid analysis of near infrared spectral technology could realize the straw and multicomponent simultaneous determination. Kuichuan sheng, Yingying Shen[21] and others were used to establish the predict model of pine, fir and three types of cotton stalk of agriculture and forestry biomass composition (moisture, ash content, volatile and fixed carbon) and calorific value, compared to the original spectrum, the accuracy of the partial least-squares regression (PLS) model based on the first derivative spectra of prediction was higher. Huali Jin[22] used near infrared spectra of near infrared spectrum analyzer to collect samples and select the appropriate spectral range and spectral preprocessing methods, used partial least squares and cross validation method to built the calibration model. The results of the determination in ash content of wheat flour samples showed that the method was feasible, and the precision was quite high. Through these texts for testing indexes of moisture, ash content, suggested that these indicators within a certain wavelength range, the spectrum technology could realize the rapid and accurate detection of these indicators.

\section{HYPERSPECTRAL TECHNOLOGY APPLIED IN COAL QUALITY INSPECTION IN THE FUTURE}

Hyperspectral image target detection in many areas had important theory value and application value, and it was a hot research problem in the fields like the current target identification and remote sensing information processing. It has been very mature technology in many areas but the application of high spectrum to coal quality testing was not mature. For coal quality index detection precision was not very accurate, so it could be deeply development. Through the literature, using infrared spectrum technology can be certain of coal-fired index detection, hyperspectral technology in the region of the visible light and infrared light has more bands and higher resolution,so we can try to use hyperspectral technology to test the coal quality indicators. The coal quality parameters including moisture, sulfur content and other parameters, according to the detection methods of moisture, sulfur content in the field of agricultural products and geological detection,we can try to apply it in coal quality testing.Hyperspectral imaging technology can be widely used in coal quality testing with the development of Image processing technology, Spectrum analysis technology and computer technology.

\section{ACKNOWLEDGEMENTS}

This work is Supported by the National Natural Science Foundation of China (No. 31401569) and the Science and Technology Development Plan of Jilin Province, China (No. 20150520135JH).

\section{REFERENCES}

[1] Han Z.J, To determine the coal quality method discussed in this paper.Electric Power Construction. 22(7) 101-107 2001.

[2] Yang M.P, Zhao D.T. Analyses the necessity and method for the determination of total sulfur in coal.Chinese science magazine. (28) 53-58 2011.

[3] Kim M.S, Chen Y.R, Mehl P.M,et al, Line hyperspectral line-scan fluorescence imaging for safety inspection of apples.Trans.of ASAE. 44(3) 72-80 2001.

[4] Kaihara M. Application of near infrared spectroscopy to rapid analysis of coals. Fuel and EnergyAbstracts. 44(4) 111-119 2003.

[5] Andres J.M,Bona M.T, Analysis of coal by diffuse reflectance near-infrared spectroscopy. Analytica Chimica Acta. 535(1-2) 123-132 2005.

[6] Andres J.M,Bona M.T, ASTM clustering for improving coal analysis by near infrared spectroscopy. Talanta.70(4) 711-719 2006. 
[7] Bona M.T, Andres J.M, Application of chemometric tools for coal classification and multivariatecalibration by transmission and drift mid-infrared spectroscopy. Analytica Chinica Acta, 624(1) 68-78 2008.

[8] Kim D.W, Lee J.M,Kim J.S, Application of near infrared diffuse reflectance spectroscopy for on-line measurement of coal properties. Korean J. Chem. Eng, 26(2) 489-495 2009.

[9] Wang Y.S,Yang M,Wei G, et al, Improved PLS regression based on SVM classification for rapidanalysis of coal properties by near-infrared reflectance spectroscopy. Sensor and Actuators B:Chemical.193 723-729 2014.

[10] Li Z,Fredericks P.M,Ward C.R, et al, Chemical functionalities of high and low sulfur Australian coals: A case study using micro attenuated total reflectance - Fourier transform infrared (ATR - FTIR) spectrometry. Organic Geochemistry.41(6) 554-558 2010.

[11] LI F.R,Xiao B.L,Tang Y.G, Application of NIR Spectra Method at On-line Analysis of Moisture in Coal. Power System Engineering.(11) 153-161 2003.

[12] Yan H.W,Chen P.Q,Lu H.S, Technology research based on NIRS quantitative test of coal sample. Coal Technology.(4) 181-188 2004.

[13] Zhai Y.Y,Chen J.B,Wu B.M, Rapid detection method based on the near-infrared diffuse reflection spectrum of ash content. Journal of Yunnan University.35(2) 214-218 2013.

[14] Li F.R,Tang Y.G,Xiao B.Y, Application of NIR Spectra Method at On-line Analysis of Moisture in Coal. Journal of Engineering for Tbermal Energy and Power.(11) 118-125 2003.

[15] Sanderson M.A,Agblevor F,Collins M,ct al, Clinical trials involving the oncolytic virus reovirus: ready for prime time. Biotnass and Biochergy. 11(5) 365-365 1996.

[16] Labbe N,Lee S.H,Cho H.W,ct al, Enhanced discrimination and calibration of biomass NIR spectral data using non-linear kernel methods. Biorecsource Technology.99(17) 445-455 2009.

[17] Allison G.G, Morris C, Hodgson E,ct al, Bioresource Technology.100(24) 64282009.

[18] Fagan C.C,Evcrard C.D,McDonnell K. Prediction of moisture, calorific value, ash and carbon content of two dedicated bioenergy crops using near-infrared spectroscopy. Bioresource Technology.102(8) 52002011.

[19] Sivakumar S.S,Qiao J,Wang N, American Society of Agricultural\&Biological Engineers Annual International Meeting, July, 9-12,2006, Portland,Oregon,. 0661832006.

[20] Huang C.J,Han L.J,Liu X, Straw industry analysis based on Near Infrared Spectroscopy. Spectroscopy and Spectral Analysis.(4) 59-66 2009.

[21] Sheng K.C,Shen Y.Y,Yang H.Q, Rapid Determination of Componential Contents and Calorific Value of Selected Agricultural Biomass Feedstocks Using Spectroscopic Technology. Spectroscopy and Spectral Analysis.(10) 220-228 2012.

[22] Jin J.H,Wang J.S, Determination of ash content in wheat flour by near-infrared spectroscopy. Journal of Henan University of Technology.(2) 135-145 2010. 